\title{
Enhanced Feedback-Related Negativity in Alzheimer's Disease
}

\author{
Eri Nitta ${ }^{1}$, Keiichi Onoda ${ }^{2}$, Fuminori Ishitobi ${ }^{1}$, Ryota Okazaki ${ }^{1}$, Seiji Mishima ${ }^{1}$, \\ Atsushi Nagai ${ }^{1}$ and Shuhei Yamaguchi ${ }^{2 *}$
}

${ }^{1}$ Central Clinical Laboratory, Shimane University Hospital, Izumo, Japan, ${ }^{2}$ Department of Neurology, Shimane University

Faculty of Medicine, Izumo, Japan

Alzheimer's disease (AD), the most common cause of dementia in the elderly, results in the impairment of executive function, including that of performance monitoring. Feedback-related negativity (FRN) is an electrophysiological measure reflecting the activity of this monitoring system via feedback signals, and is generated from the anterior cingulate cortex. However, there have been no reports on FRN in AD. Based on prior aging studies, we hypothesized that FRN would decrease in AD patients. To assess this, FRN was measured in healthy individuals and those with AD during a simple gambling task involving positive and negative feedback stimuli. Contrary to our hypothesis, FRN amplitude increased in AD patients, compared with the healthy elderly. We speculate that this may reflect the existence of a compensatory mechanism against the decline in executive function. Also, there was a significant association between FRN amplitude and depression scores in AD, and the FRN amplitude tended to increase insomuch as the Self-rating Depression Scale (SDS) was higher. This result suggests the existence of

OPEN ACCESS

Edited by:

Raffaella Franciotti,

University of Chieti-Pescara, Italy

Reviewed by:

Hidenao Fukuyama, Kyoto University, Japan Márk Molnár, Institute of Cognitive Neuroscience and Psychology (MTA), Hungary

${ }^{*}$ Correspondence: Shuhei Yamaguchi yamagu3n@med.shimane-u.ac.jp

Received: 20 December 2016 Accepted: 27 March 2017 Published: 28 April 2017

Citation:

Nitta E, Onoda K, Ishitobi F, Okazaki R, Mishima S, Nagai A and Yamaguchi S (2017) Enhanced Feedback-Related Negativity in Alzheimer's Disease.

Front. Hum. Neurosci. 11:179. doi: 10.3389/fnhum.2017.00179 a negative bias in the affective state in $A D$. Thus, the impaired functioning monitoring system in $A D$ is a more complex phenomenon than we thought.

Keywords: Alzheimer's disease, monitoring systems, feedback-related negativity, depression, aging

\section{INTRODUCTION}

Executive function is a set of cognitive processes including attentional control, working memory and planning, and so on, and is necessary for selecting and successfully monitoring behavior (Alvarez and Emory, 2006; Chan et al., 2008; Diamond, 2013). Executive function is impaired in individuals with dementia, including those suffering from Alzheimer's Disease (AD) (Collette et al., 1999; Perry and Hodges, 1999). Monitoring is a part of the executive function, and is the ability to monitor one's own actions and responses during task performance in order to detect and correct errors. Impairment of executive function in $\mathrm{AD}$ patients is involved in the failure of self-monitoring (Ott et al., 1996), which may underlie subtle difficulties in coping with daily activities (Perry and Hodges, 1999). It has been suggested that deficits in self-monitoring occur after damage to the frontal lobes and other cerebral areas (Ott et al., 1996).

Feedback-Related Negativity (FRN) is a neurophysiological index that reflects the monitoring process associated with feedback inputs. FRN has been shown to be elicited by feedback stimuli (particularly negative stimuli) in a gambling task (Gehring, 2002; Hajcak et al., 2006; Holroyd et al., 2006) and a time production task (Miltner et al., 1997; Wild-Wall et al., 2009; Becker et al., 2014). This negative potential appears at a latency of 200-300 ms after feedback (Miltner et al., 1997; Falkenstein et al., 2000; Gehring, 2002; Holroyd and Coles, 2002; Nieuwenhuis et al., 2004), 
and is primarily distributed over the frontal-central scalp area. Generally, FRN means the negative peak obtained by subtracting the waveform for the positive feedback from that for the negative feedback, or the negative waveform obtained from the negative feedback. A great amount of evidence indicates that FRN is generated in the anterior cingulate cortex (Holroyd and Coles, 2002; Hajcak et al., 2007; Bellebaum and Daum, 2008; Holroyd et al., 2009). FRN codes negative prediction errors in the context of varying reword probabilities and magnitudes (Cohen et al., 2007; Bellebaum and Daum, 2008; Wu and Zhou, 2009; Bellebaum et al., 2010). As with other components of eventrelated evoked potentials (ERPs), many studies have revealed that FRN amplitude is reduced and its latency prolonged in the elderly compared to that in young individuals (Eppinger et al., 2008; Mathewson et al., 2008; Wild-Wall et al., 2009; Hämmerer et al., 2011; Pietschmann et al., 2011a), although some studies show no such age differences in FRN (Bellebaum et al., 2011). However, in line with the FRN aging effects, $\mathrm{AD}$ patients might show alterations of FRN. However, no reports have investigated the changes in FRN in AD patients.

Error-Related Negativity (ERN) is an ERP component elicited by an individual's own behavioral errors. ERN measures may also provide insights to the monitoring system. Some reports have demonstrated that ERN amplitude decreases in older participants (Gehring and Knight, 2000; Falkenstein et al., 2001; Nieuwenhuis et al., 2002; Pietschmann et al., 2011a,b; Schreiber et al., 2011; Endrass et al., 2012), and is further reduced in AD patients with prolonged latency (Mathalon et al., 2003). Considering its similarity to ERN, this evidence suggests that FRN should also demonstrate decreased amplitude and delayed latency in $\mathrm{AD}$ patients.

P300 is a positive component at the dominantly parietal area approximately $300 \mathrm{~ms}$ after stimulus onset (Sutton et al., 1965), and is elicited typically by an oddball task, i.e., auditory, visual, olfactory or somatosensory stimuli (Yamaguchi and Knight, 1991a,b; Frodl et al., 2002; Polich, 2004; Bennys et al., 2007; Golob et al., 2007). This component reflects various cognitive processes, including context updating (Donchin, 1981; Polich, 2007), resource allocation (Wickens et al., 1983; Kramer et al., 1985; Polich, 2007), memory encoding (Karis et al., 1984; Fabiani et al., 1990; Johnson, 1995; Polich, 2007) and attention, stimulus evaluation, judgment and decision-making (Becker and Shapiro, 1980; Duncan-Johnson and Donchin, 1982; Kramer and Strayer, 1988; Katada et al., 2004; Gironell et al., 2005). There are many regions in the brain, especially in the parietal, temporal, prefrontal cortex and hippocampus, that contribute to its generation (Yamaguchi and Knight, 1991a; Halgren et al., 1998; Tarkka and Stokic, 1998; Kirino et al., 2000; Kiehl et al., 2001). P300 amplitude and latency are modulated by a variety of factors, including subjective probability of stimuli, stimulus saliency, availability of attentional resources (Kutas et al., 1977; Polich, 1986; Kramer and Strayer, 1988; Gonsalvez and Polich, 2002), and memory performance (Fabiani et al., 1990; Johnson, 1995). P300 has been proposed as one of the electrophysiological biomarkers of dementia (Olichney et al., 2011; Howe et al., 2014), and its usefulness has been well documented in the early diagnosis of dementia (Polich et al., 1990; Juckel et al., 2008;
Ahiskali et al., 2009; Chapman et al., 2011; Vecchio and Määttä, 2011). Elderly people show a decreased amplitude and prolonged latency of P300, and these changes are more pronounced in dementia (Polich and Corey-Bloom, 2005; Bennys et al., 2007; Lai et al., 2010; Parra et al., 2012). We speculate that these findings regarding P300 may also be applicable to feedback stimuli.

Previous studies have also claimed that FRN and P300 encode different aspects of outcome evaluations (Yeung and Sanfey, 2004). These suggest that outcome evaluation can be roughly divided into two related processes: one is an early evaluation of the cognitive or motivational significance of feedback stimuli, which relates to FRN; and the other is a more elaborative evaluation of feedback stimuli, which is affected by the allocation of attentional resources such as intentionality or expectancy and is related to P300. Furthermore, other research has reported that FRN is sensitive not only to reward valence and magnitude, but also to expectancy towards reward magnitude. While P300 is sensitive to both feedback valence and reward magnitude, this sensitivity can be modulated by expectancy towards reward magnitude (Wu and Zhou, 2009). These findings suggest that FRN may play a role as a general mechanism that evaluates whether an outcome is consistent or inconsistent with expectations; whereas P300 is sensitive to the later, top-down controlled process of outcome evaluation, which links with the allocation of attentional resources, including reward valence, reward magnitude and magnitude expectancy. In AD patients, these processes of outcome evaluation for feedback stimulus are considered to be impaired.

Accordingly, we investigated the monitoring system of $\mathrm{AD}$ patients using a neurophysiological measure (i.e., FRN), in a gambling task. We hypothesized that, compared with healthy elderly people and healthy young people, the amplitude of FRN would be reduced, and latency delayed in $\mathrm{AD}$ patients due to disruption of feedback processing.

\section{MATERIALS AND METHODS}

\section{Participants}

Twenty-four patients with (AD; 15 males, 9 females, age range from 66 to 75 , mean age $=71.5, \mathrm{SD}=2.8), 20$ healthy older subjects (HO; 13 males, 10 females, age range from 62 to 79 , mean age $=69.6, \mathrm{SD}=6.0$ ), and 19 healthy young subjects (HY; 10 males, 9 females, age range from 19 to 28 , mean age $=22.2, \mathrm{SD}=2.2$ ) participated in this study. The $\mathrm{AD}$ patients met the National Institute of Neurological and Communicative Disorders and Stroke and the $\mathrm{AD}$ and Related Disorders Association (NINCDS/ADRDA) criteria for individuals with $\mathrm{AD}$. Their scores on the Mini-Mental State Examination (MMSE) were $19.3 \pm 3.9$, and on the Clinical Dementia Rating $(\mathrm{CDR})$ were $1.1 \pm 0.4$, (21 patients for CDR 1 , and 3 patients for CDR 2). All participants had normal or corrected-to-normal vision. Virtually all participants were righthanded, with three exceptions (one in each group). Participants in the $\mathrm{HO}$ and $\mathrm{HY}$ groups had no history of neurological or psychiatric diseases. Finally, this study was approved by the ethics 
committee of the Shimane University. All participants provided signed informed consent following our explanation of the study's purpose and protocols.

\section{Neuropsychological Assessment}

$\mathrm{AD}$ and $\mathrm{HO}$ participants were assessed using neuropsychological test batteries that included the Mini Mental State Examination (MMSE; Folstein et al., 1975), the Frontal Assessment Battery (FAB; Dubois et al., 2000), the Word Fluency Test (WFT; vegetable for the semantic category), the Self-rating Depression Scale (SDS; Zung, 1965), and the Apathy Scale (AS; Okada et al., 1998). These assessments were conducted by a trained clinical researcher within the 2-week period before the ERP experiment.

\section{Task, Stimuli and Procedure}

In the experiment conducted for this study, each participant performed a simple gambling task (Figure 1). Participants were comfortably seated approximately $1.5 \mathrm{~m}$ in front of a computer screen in an electrically shielded and sound-attenuated room. At the start of each trial, a depiction of the choice display was presented on a screen, which lasted until a participant made a response. The picture consisted of two colored squares with green and purple presented on the left and right screen sides respectively, and the relationship between the color and position was consistently maintained for all individuals. We instructed

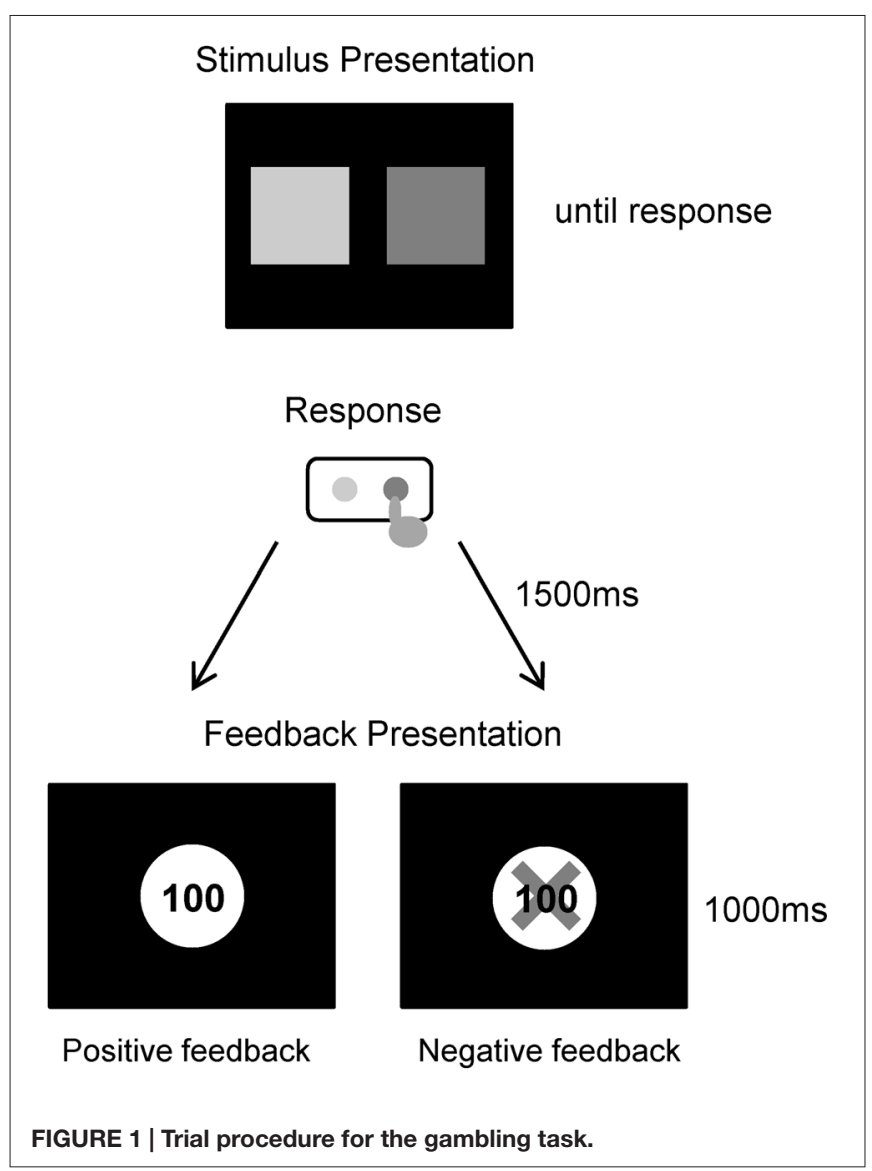

participants that they could win money by correctly choosing one of the squares. Participants then chose one of the two squares by pressing one of two corresponding buttons (i.e., left or right). A feedback stimulus appeared $1.5 \mathrm{~s}$ after the choice picture was turned off, and lasted for $1 \mathrm{~s}$. The feedback stimulus consisted of a display of a win or loss. If the selected box was a win, a 100 yen (about 1 USD) coin appeared in the center of the screen. If the selected box was a loss, a 100 yen coin was presented with a superimposed red $\mathrm{X}$. The next trial started following an inter-trial interval of 2-3 s. The experiment consisted of 120 trials (two blocks of 60 trials each). The probabilities of winning and losing for each option was equal (50\%), and this was same in all three groups. Participants were told that they would be participating in a virtual game; they were instructed to try to maximize their monetary rewards. Participants performed 10 practice trials before the experiment. Total task duration including 2 blocks and rest was about 15-20 $\mathrm{min}$, and the whole experiment including the installation and removal of electrodes lasted about $1 \mathrm{~h}$.

\section{Electroencephalography (EEG) Recording and Data Reduction}

The electroencephalogram (EEG) was obtained from $21 \mathrm{Ag} / \mathrm{AgCl}$ electrodes at the positions of the International 10-20 System: midline ( $\mathrm{FPz}, \mathrm{Fz}, \mathrm{Cz}, \mathrm{Pz}, \mathrm{Oz})$; frontal (Fp1, Fp2, F3, F4, F7, F8); central (C3, C4); temporal (T3, T4, T5, T6); parietal (P3, $\mathrm{P} 4)$; occipital (O1, O2); and was referenced to the linked mastoids. Horizontal and vertical electrooculograms (EOG) were recorded at sites lateral to the left and right outer canthi, and above and below each eye. Impedances were kept below $5 \mathrm{k} \Omega$ for each electrode. The EEG signals were recorded using the BrainAmp amplifier (Brain Products, Munich, Germany) with appropriate software. The EEG signals were recorded continuously with a band pass set at $0.01-250 \mathrm{~Hz}$, and a sampling frequency of $500 \mathrm{~Hz}$. In addition, each participant's reaction time (RT) was measured simultaneously with the EEG recording.

\section{Event-Related Potentials (ERPs)}

EEG data were analyzed off-line using the BrainVision Analyzer 2 software (Brain Products, Munich, Germany). An independent component analysis (ICA) was performed on single-subject EEG data in order to correct for blink artifacts. All segments exceeding $\pm 100 \mu \mathrm{V}$ were rejected as artifacts. EEG epochs were extracted beginning $200 \mathrm{~ms}$ before and ending $800 \mathrm{~ms}$ after the presentation of feedback for win and loss conditions, separately. A baseline was set at the duration of $200 \mathrm{~ms}$ prior to feedback stimulus onset. ERP peak amplitude and latency were derived from each individual's average waveform. The FRN was semi-automatically measured as the most negative peak within the time window of $150-400 \mathrm{~ms}$ after feedback presentation, and was finally identified by visual inspection. P300 was measured as the most positive peak within the time window of $300-600 \mathrm{~ms}$ in the same way. The additional FRN measures were computed for each participant by subtracting the waveform after positive feedback from that after negative feedback. The peak amplitudes and latencies of the components 
were derived from the resulting difference wave within the time window of 150-450 ms.

\section{Statistics}

We conducted $t$-tests on the demographic (except for the $\chi^{2}$ test for sex) and neuropsychological data to allow comparison of $\mathrm{AD}$ and HO. To check each participant's understanding of the task, we calculated switching response ratios following negative and positive feedback, respectively. A higher switching ratio for negative feedback than for positive feedback means that participants had a tendency to avoid the option with the last negative feedback, and were able to understand the gambling task. Therefore, we compared the switching ratios between preceding negative and positive feedback using paired $t$-tests in each group. A one-way analysis of variance (ANOVA) was used to analyze the RT data, and a two-way repeated measures ANOVA (group $\times$ channel, or group $\times$ feedback condition) was performed (separately) for the amplitudes and latency of ERP components. The statistical criterion was set at a $p$ value of less than 0.05, and Tukey method analysis was used for post hoc tests. Partial correlation analyses were also conducted to examine the relationships between the ERP components and the neuropsychological data.

\section{RESULTS}

\section{Neuropsychological and Behavioral Data}

The background, neuropsychological and behavior data are summarized in Table 1. There were no significant differences in age and gender ratios between $\mathrm{AD}$ and $\mathrm{HO}$. However, independent $t$ tests revealed that there were significant differences between $\mathrm{AD}$ and $\mathrm{HO}$ on the cognitive function scores (MMSE, FAB, WFT), and that AD showed reduced cognitive function compared to $\mathrm{HO}(t \mathrm{~s}(45)>5.0$, ps $<0.001)$. However, affective function scores did not differ between those groups ( $t$ s $(45)<1.9$, ps $>0.068)$. RT in the gambling task was delayed significantly in $\mathrm{AD}$ and $\mathrm{HO}$ compared to that in
HY ( $p s<0.001)$. Switching response ratio was higher for the following negative feedback than positive feedback in every three groups $(p s<0.05)$.

\section{ERP Waveforms}

Figure 2 presents the feedback-locked ERP waveforms at the three midline sites, $\mathrm{Fz}, \mathrm{Cz}$ and $\mathrm{Pz}$, for positive and negative conditions in each group. In both conditions, FRN appeared at a latency range of 200-400 ms, and P300 appeared at a latency of 300-500 ms. A difference in FRN amplitude between the positive and negative conditions was observed clearly at $\mathrm{Fz}, \mathrm{Cz}$ and $\mathrm{Pz}$ in $\mathrm{AD}$. The FRN difference in HY was also as apparent as that in $\mathrm{AD}$, but not in HO. On the other hand, P300 amplitude was reduced markedly in $\mathrm{AD}$. The $\mathrm{P} 300$ amplitude in $\mathrm{HY}$ was the largest among the three groups, and P300 in HO was lower than that observed in the HY group.

Figure 3 displays the difference waves formed by subtracting the ERP for the positive feedback from that for the negative feedback in each group. Here, FRN is the negative deflection in the time window of 200-400 ms after feedback stimuli. The FRN in the $\mathrm{AD}$ group showed larger amplitude and prolonged latency compared to that in the HO group. However, the FRN amplitude in HY group was almost the same as that in the $\mathrm{AD}$ group, but its latency was shorter than in the latter group. Finally, HO showed smaller FRN amplitude and delayed latency compared to HY.

\section{FRN in Difference Waves}

The upper row in Figure 4 presents the FRN peak amplitude (left panel) and peak latency (right panel) for the three groups; Table 2 gives the ANOVA results. The ANOVA revealed that the main effect of group for amplitude was significant $\left(F_{(2,63)}=4.1\right.$, $\varepsilon=0.69, p=0.021)$. Post hoc tests indicated the amplitude in AD was significantly larger than that in $\mathrm{HO}(p=0.015)$. However, the main effect of channel did not reach significance $\left(F_{(2,63)}=3.0\right.$, $\varepsilon=0.69, p=0.053)$, nor was interaction of group by channel $\operatorname{significant}\left(F_{(4,126)}=1.2, \varepsilon=0.69, p=0.296\right)$.

Regarding latency, the main effects of group and channel were significant $\left(\mathrm{Fs}_{(2,63)}>6.3, \varepsilon=0.73\right.$, ps $\left.<0.003\right)$. Post hoc

TABLE 1 | Participants' background, neuropsychological data and behavioral data.

\begin{tabular}{lcccr}
\hline & AD & HO & HY & p \\
\hline$N$ & 24 & 25 & 19 & 0.181 \\
Age (years) & $71.5 \pm 2.8$ & $69.6 \pm 6.0$ & $22.0 \pm 2.2$ & $10 / 9$ \\
Sex (M/F) & $15 / 9$ & $13 / 10$ & - & $<.684$ \\
MMSE & $19.3 \pm 3.9$ & $28.9 \pm 1.9$ & - & $<001$ \\
FAB & $10.8 \pm 3.4$ & $16.0 \pm 1.1$ & - & $<0.001$ \\
WFT & $8.7 \pm 4.8$ & $15.1 \pm 3.6$ & - & 0.357 \\
SDS & $32.5 \pm 7.4$ & $30.7 \pm 6.5$ & $679 \pm 395$ & 0.068 \\
AS & $12.7 \pm 8.3$ & $9.0 \pm 4.7$ & $0.56 \pm 0.17$ & $<0.001$ \\
RT (ms) & $1884 \pm 834$ & $1027 \pm 319$ & $0.38 \pm 0.22$ & $<0.001$ \\
SR ratio following NF & $0.60 \pm 0.18$ & $0.67 \pm 0.15$ &
\end{tabular}

Data are shown in mean and standard deviation format. All p-values except for $S R$ ratio indicate results of the comparisons between Alzheimer's disease (AD) and healthy old (HO). The $p$-value of the SR ratio shows results of the comparisons between following Negative feedback and following Positive feedback in all groups. HY means healthy young. MMSE, Mini Mental State Examination; FAB, Frontal Assessment Battery; WFT, Word Fluency Test; SDS, Self-rating Depression Scale; AS, Apathy Scale; $R T$, Reaction time in gambling task; SR ratio, Switching Response ratio in gambling task; NF, Negative feedback; PF, Positive feedback. 


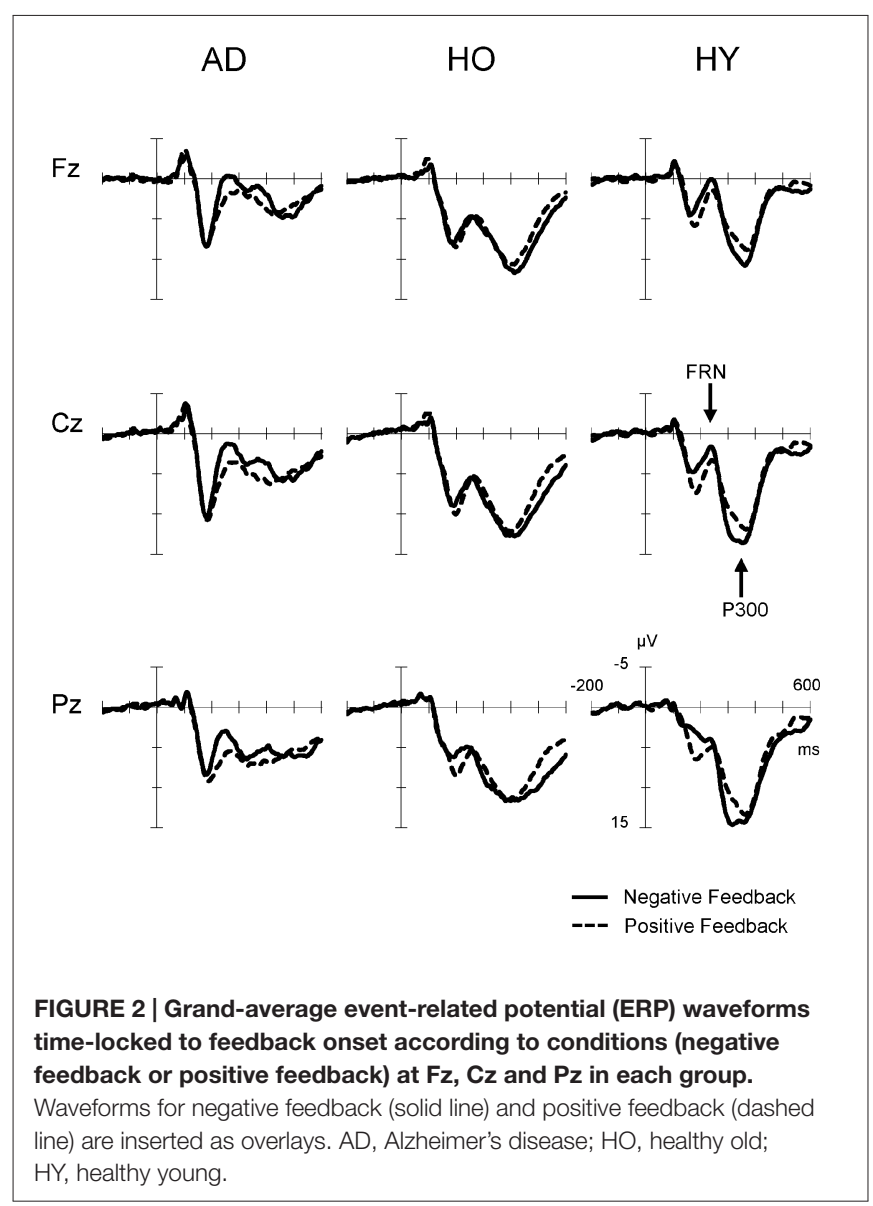

tests denoted that the latency was prolonged significantly in $\mathrm{AD}$ compared to HY ( $p=0.002)$, although there was no significant interaction of group by channel $\left(F_{(4,126)}=0.7, \varepsilon=0.73, p=0.602\right)$.

\section{FRN}

We also examined group differences for the FRN component. The results appear in the middle row of Figure 4 and in Table 3. The ANOVA for the amplitude yielded significant main effects of group at $\mathrm{Fz}$ and $\mathrm{Cz}\left(F_{(2,63)}>5.0\right.$, ps $\left.<0.010\right)$. Post hoc tests showed that $\mathrm{FRN}$ at $\mathrm{Fz}$ and $\mathrm{Cz}$ were larger for $\mathrm{AD}$ compared to $\mathrm{HO}$ in both positive and negative conditions ( $p$ s $<0.028)$. All channels showed significant main effect of condition $\left(F_{(2,63)}>17.6\right.$, ps $\left.<0.001\right)$. No significant interaction of group by condition was observed $\left(F s_{(4,126)}<2.9\right.$, ps $>0.062$ ).

For the analysis of latency, significant main effects of group and condition were found at all channels $\left(F_{(2,63)}>10.9\right.$, ps $<0.002)$. Post hoc tests indicated that the latency at $\mathrm{Fz}$ and $\mathrm{Cz}$ were significantly delayed in $\mathrm{AD}$ and $\mathrm{HO}$ compared to that in $\mathrm{HY}$ in both conditions ( $p s<0.043$ ). There were no significant interactions for group by condition $\left(F s_{(4,126)}>0.2\right.$, $\left.p s>0.794\right)$.

\section{P300}

The analysis for P300 is also depicted in the lower rows of Figure 4 and Table 3. Significant interactions of group by

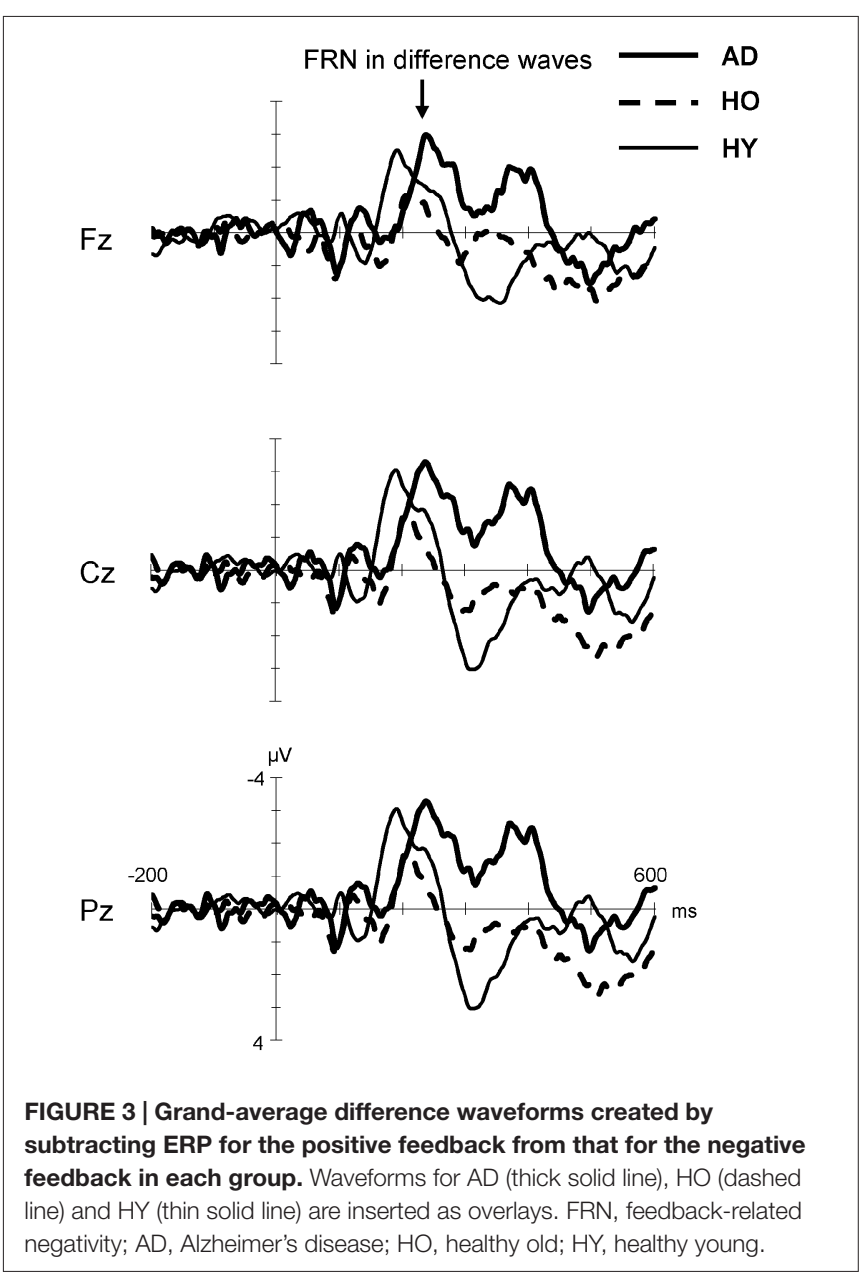

condition were observed at $\mathrm{Cz}$ and $\mathrm{Pz}\left(F_{(4,126)}>4.1, p s<0.022\right)$. Post hoc tests indicated that the amplitudes were significantly smaller in $\mathrm{AD}$ than those in $\mathrm{HO}$ and $\mathrm{HY}$ in both conditions ( $p$ s $<0.028)$. There was a tendency for the amplitude to be larger for negative feedback than for positive feedback at $\mathrm{Cz}$ and $\mathrm{Pz}$ in $\mathrm{HY}(p s<0.087)$, while there was no significant difference between the two types of feedback in $\mathrm{AD}$ and HO.

With regard to latency, significant interactions of group by condition were observed at $\mathrm{Cz}$ and $\mathrm{Pz}\left(F \mathrm{~s}_{(4,126)}>3.3\right.$, ps $<$ 0.043). Post hoc tests indicated that latency was delayed in $\mathrm{AD}$ and $\mathrm{HO}$ compared with $\mathrm{HY}$ in both positive and negative conditions ( $p s<0.032$ ). Additionally, latency in $\mathrm{AD}$ was more prolonged than $\mathrm{HO}$ for negative feedback $(p s<0.032)$, but this was not the case for positive feedback.

\section{Correlation between Neuropsychology and ERP}

We also performed correlation analyses between the neuropsychological data and the ERP measurements for groups $\mathrm{AD}$ and $\mathrm{HO}$ (Table 4, Figure 5); and found that there was a significant association between the FRN amplitude in difference 


\section{FRN in difference waves}
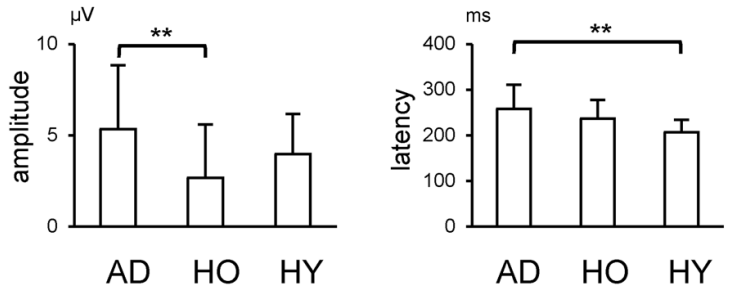

\section{FRN}
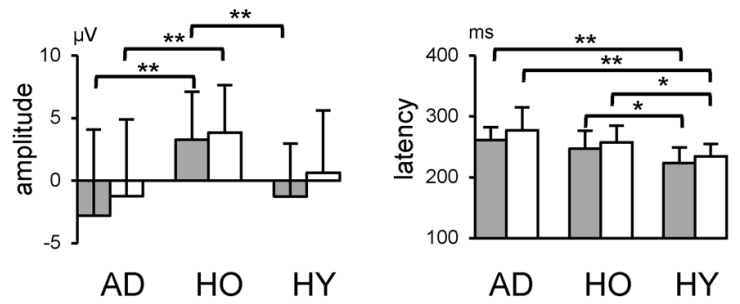

P300
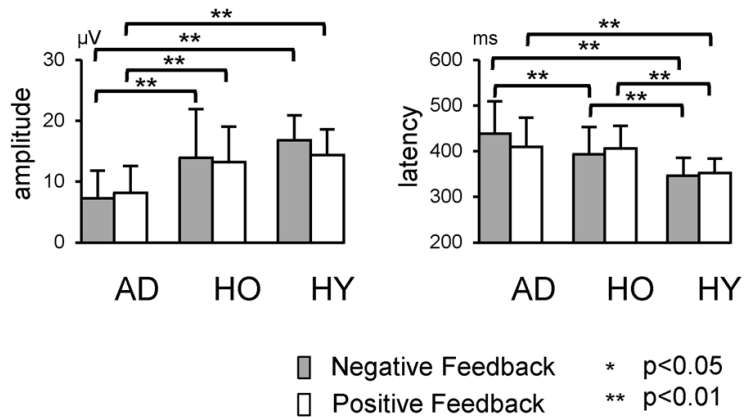

FIGURE 4 | Each row shows data relating to FRN at Fz and P300 at Pz, respectively. Error bars denote standard deviations.

waves and SDS at $\mathrm{Cz}$ in $\mathrm{AD}(r=-0.495, p=0.023)$, but not in $\mathrm{HO}(r=0.227, p=0.309)$. A direct comparison revealed that the correlation coefficients of the two groups differed significantly $(p<0.05)$. There were significant correlations between FRN amplitude and WFT scores in AD for both conditions ( $r s>0.46$, ps < 0.05). P300 amplitudes were positively correlated with WFT scores in both conditions in $\mathrm{AD}(p s<0.05)$, and positive feedback in HC ( $p s<0.01)$. There were no noticeable correlations between ERP latencies and cognitive function test scores.

\section{DISCUSSION}

The aim of this study was to examine the changes in the monitoring system of $\mathrm{AD}$ patients and healthy control participants (HO) during gambling tasks using FRN. Results reveal that the $\mathrm{AD}$ group showed a larger amplitude and a delayed latency of FRN compared to the HO group, and the FRN amplitude correlated with cognitive function scores. This study revealed electrophysiological abnormalities of the monitoring function in $\mathrm{AD}$. However, the increased amplitude of FRN in AD was unexpected. It is the opposite of predictions made from the original hypothesis.

The original hypothesis relating to changes in FRN for the $\mathrm{AD}$ group was based on prior evidence of aging effects on FRN. Many researchers have reported decreases in FRN amplitude associated with aging (Eppinger et al., 2008; Mathewson et al., 2008; Wild-Wall et al., 2009; Hämmerer et al., 2011; Pietschmann et al., 2011a), and our results also replicated this aging effect. ERN is also known to be affected by aging, with elderly people typically showing smaller ERN than young people (Gehring and Knight, 2000; Falkenstein et al., 2001; Nieuwenhuis et al., 2002). Several research groups have reported that the impairment of error processing and learning in older adults is the result of age-related changes in the mesencephalic dopamine system, such as the loss of dopamine receptors and the deterioration of dopaminergic receptor binding with aging (Volkow et al., 1998; Bäckman et al., 2000; Kaasinen et al., 2000). Based on findings that the efficiency of the dopamine system declines with age, Nieuwenhuis et al. (2002) extended reinforcement learning theory to older adults. They proposed that weakened phasic activity of the midbrain dopamine system leads to reduced negative reinforcement learning signals; implying that elderly people are learning impaired compared to younger adults (Nieuwenhuis et al., 2002). We had expected that this aging effect would be most pronounced in $\mathrm{AD}$, which would mean that $\mathrm{AD}$ patients would exhibit smaller amplitudes in monitoring responses. A previous ERN study had indeed reported that amplitudes decreased for $\mathrm{AD}$ patients compared to healthy elderly people (Mathalon et al., 2003). However, in contrast to the results of that previous study, we found a significant increase of FRN amplitude in $\mathrm{AD}$ patients.

First of all though, whether AD patients in our study could understand the gambling task is a problem when we try to explain this result. Nevertheless, some behavioral studies have reported that $\mathrm{AD}$ patients have accomplished more complex tasks like the Iowa Gambling Task (Sinz et al., 2008). In our study, moreover, the switching ratio following the feedback was larger for the negative feedback than the positive feedback in all groups, suggesting that even $\mathrm{AD}$ patients could distinguish

TABLE 2 | Repeated two-way ANOVA (group x channel) for feedback-related negativity (FRN) in difference waves data.

\begin{tabular}{|c|c|c|c|c|c|c|}
\hline & \multicolumn{2}{|c|}{ Main effect of group } & \multicolumn{2}{|c|}{ Main effect of channel } & \multicolumn{2}{|c|}{ Interaction (group $\times$ channel) } \\
\hline & $\boldsymbol{F}$ & $p$ & $\boldsymbol{F}$ & $p$ & $\boldsymbol{F}$ & $p$ \\
\hline FRN peak amplitude & 4.1 & 0.021 & 3.0 & 0.053 & 1.2 & 0.296 \\
\hline FRN peak latency & 6.3 & 0.003 & 7.6 & 0.001 & 0.7 & 0.602 \\
\hline
\end{tabular}

Significant p-values are in BOLD. 
TABLE 3 | Repeated two-way ANOVA (group x condition) for FRN and P300 data.

\begin{tabular}{|c|c|c|c|c|c|c|}
\hline & \multicolumn{2}{|c|}{ Main effect of group } & \multicolumn{2}{|c|}{ Main effect condition } & \multicolumn{2}{|c|}{ Interaction (group $\times$ condition) } \\
\hline & $F$ & $p$ & $\boldsymbol{F}$ & $p$ & $F$ & $p$ \\
\hline \multicolumn{7}{|c|}{ FRN peak amplitude } \\
\hline $\mathrm{Fz}$ & 7.6 & 0.001 & 17.6 & $<0.001$ & 1.6 & 0.216 \\
\hline $\mathrm{Cz}$ & 5.0 & 0.010 & 28.1 & $<0.001$ & 2.9 & 0.062 \\
\hline $\mathrm{Pz}$ & 1.3 & 0.270 & 44.7 & $<0.001$ & 1.5 & 0.227 \\
\hline \multicolumn{7}{|c|}{ FRN peak latency } \\
\hline $\mathrm{Fz}$ & 15.4 & $<0.001$ & 10.9 & 0.002 & 0.2 & 0.794 \\
\hline $\mathrm{Cz}$ & 15.2 & $<0.001$ & 14.9 & $<0.001$ & 0.1 & 0.975 \\
\hline $\mathrm{Pz}$ & 12.9 & $<0.001$ & 22.1 & $<0.001$ & 0.1 & 0.977 \\
\hline \multicolumn{7}{|c|}{ P300 peak amplitude } \\
\hline $\mathrm{Fz}$ & 11.8 & $<0.001$ & 10.6 & 0.002 & 2.1 & 0.129 \\
\hline $\mathrm{Cz}$ & 10.9 & $<0.001$ & 6.2 & 0.016 & 4.1 & 0.022 \\
\hline $\mathrm{Pz}$ & 14.1 & $<0.001$ & 3.0 & 0.086 & 4.6 & 0.014 \\
\hline \multicolumn{7}{|c|}{ P300 peak latency } \\
\hline $\mathrm{Fz}$ & 28.6 & $<0.001$ & 0.9 & 0.334 & 3.1 & 0.053 \\
\hline $\mathrm{Cz}$ & 16.6 & $<0.001$ & 0.8 & 0.371 & 4.0 & 0.023 \\
\hline $\mathrm{Pz}$ & 13.7 & $<0.001$ & 0.3 & 0.615 & 3.3 & 0.043 \\
\hline
\end{tabular}

Significant $p$-values are in BOLD.

TABLE 4 | Correlation coefficients between neuropsychological data and amplitudes of event-related potential (ERP).

\begin{tabular}{|c|c|c|c|c|c|c|c|c|c|c|}
\hline & \multirow{2}{*}{\multicolumn{2}{|c|}{$\begin{array}{c}\text { FRN in difference } \\
\text { waves }\end{array}$}} & \multicolumn{4}{|c|}{ FRN } & \multicolumn{4}{|c|}{ P300 } \\
\hline & & & \multicolumn{2}{|c|}{ Negative } & \multicolumn{2}{|c|}{ Positive } & \multicolumn{2}{|c|}{ Negative } & \multicolumn{2}{|c|}{ Positive } \\
\hline & $A D$ & HO & $A D$ & HO & $A D$ & HO & $A D$ & HO & $A D$ & $\mathrm{HO}$ \\
\hline MMSE & -0.02 & -0.10 & 0.01 & 0.15 & 0.01 & 0.14 & 0.03 & 0.13 & 0.14 & 0.16 \\
\hline FAB & 0.22 & -0.17 & 0.22 & 0.10 & 0.12 & 0.07 & 0.01 & 0.12 & -0.05 & 0.03 \\
\hline WFT & 0.23 & -0.17 & $0.53^{*}$ & 0.22 & $0.46^{*}$ & 0.35 & $0.59^{* *}$ & 0.39 & $0.45^{*}$ & $0.60^{* *}$ \\
\hline SDS & $-0.50^{*}$ & 0.23 & -0.05 & -0.23 & 0.08 & -0.24 & -0.01 & 0.07 & 0.19 & -0.18 \\
\hline AS & -0.33 & 0.01 & -0.09 & -0.35 & -0.01 & -0.39 & -0.06 & -0.04 & 0.05 & -0.20 \\
\hline
\end{tabular}

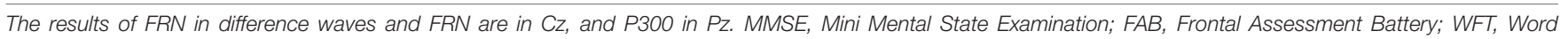

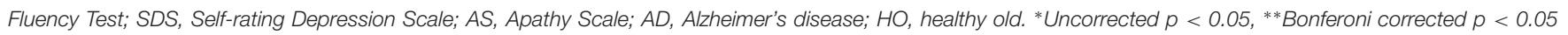
(=uncorrected $p<0.05 / 6$ ).

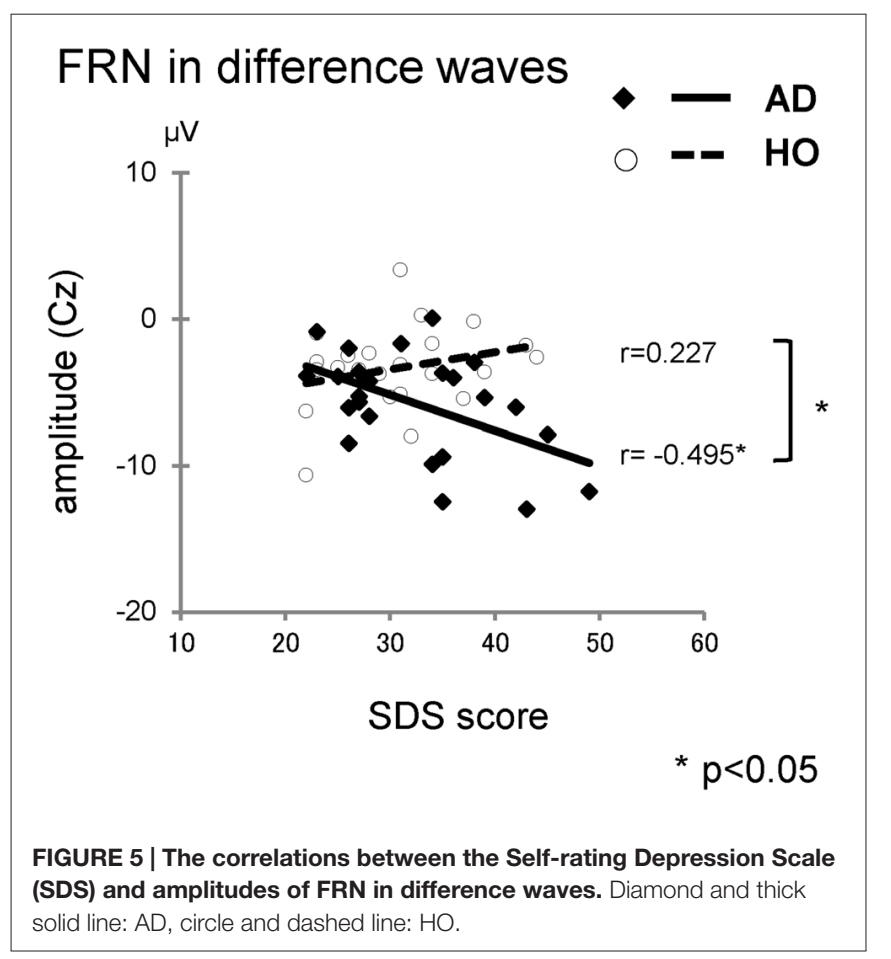

between positive and negative stimuli, and could avoid the options associated with recent negative results. Therefore, the negative component obtained from the differential waveform in $\mathrm{AD}$ could be considered as FRN.

As a result, we demonstrated that $\mathrm{AD}$ patients show a higher FRN. It is already known that the source of FRN is located in the ACC (Holroyd and Coles, 2002; Hajcak et al., 2007; Bellebaum and Daum, 2008; Holroyd et al., 2009), and abnormalities of the ACC in AD have been reported at histopathological and physiological levels. In $\mathrm{AD}$ patients, accumulation of both beta amyloid and tau (Morishima-Kawashima and Ihara, 2002; Leuba et al., 2009; Murphy and LeVine, 2010; Bloom, 2014), metabolic changes (Bracco et al., 2007; Lim et al., 2012), and decreased blood flows (Dukart et al., 2013; Long et al., 2013; Terada et al., 2013; Lin et al., 2014; Bailly et al., 2015) are observed in the ACC. The ACC is atrophied structurally (Buckner et al., 2005; Jones et al., 2006; Seeley et al., 2009; Krueger et al., 2010), and the anatomical connectivity with other areas is also impaired (Greicius et al., 2004; Rombouts et al., 2005; Wang et al., 2007; Boublay et al., 2016; Hafkemeijer et al., 2016b). On the other hand, higher functional connectivity of the ACC for the salience network has been reported in some resting-state fMRI studies for AD (Zhou et al., 2010; Hafkemeijer et al., 2016a). The salience network plays a crucial role in the detection of salient events from 
internal and external information (Seeley et al., 2007), therefore the network is inevitably involved in monitoring processing. The enhanced functional connectivity of the ACC in AD is dovetailed with the enhanced FRN in our study in the context of intensified detection of salient feedback information. Thus, the influence of $\mathrm{AD}$ pathology on the ACC function might be affected depending on the segregated functional network of the ACC.

One of the possible mechanisms for explaining this discrepancy is the compensation-related utilization of neural circuits hypothesis (CRUNCH; Grady, 2012). The idea of CRUNCH is that more neural resources are recruited by the elderly at low levels of cognitive load (when tasks are easier) than younger adults, who do not need them. At higher load levels, this compensatory mechanism is not effective, leading to less activation in elderly compared with young adults. This could apply to the relationship between $\mathrm{AD}$ and the healthy elderly (Grady, 2012). According to CRUNCH, enhanced FRN reflects a compensatory mechanism with larger recruitment of neural activity in $\mathrm{AD}$ patients compared to younger adults. Younger adults in our study might search a best strategy or hidden rule to get a better performance although the probabilities of positive and negative feedbacks were truly equal and the sequence was completely random.

Another idea that might explain the discrepancy is obtained from ERP studies of other diseases. A similar discrepancy between FRN and ERN has been reported in several psychiatric diseases in young people (van Meel et al., 2005, 2011; Groen et al., 2008; Holroyd et al., 2008; Vlamings et al., 2008; South et al., 2010; Larson et al., 2011; Santesso et al., 2011). Studies investigating FRN and ERN in children with autism have demonstrated that a robust FRN is equally elicited in children with autism and those with typical development (Larson and Clayson, 2011; Larson et al., 2011; McPartland et al., 2012; Stavropoulos and Carver, 2014), but ERN amplitude is significantly attenuated in autistic children (Vlamings et al., 2008; South et al., 2010; Santesso et al., 2011; Sokhadze et al., 2011, 2012; McMahon and Henderson, 2015). These results imply that individuals with autism may process external and concrete feedback normally, but have difficulty with the internal and more abstract regulation of performance. Similar neurophysiological mechanisms may be operative in $\mathrm{AD}$ patients.

As well as our FRN research in AD, there are several reports that have demonstrated FRN enlargement in other diseases. In depressed patients, augmentation of FRN amplitude has been reported (Tucker et al., 2003; Santesso et al., 2008; Cavanagh et al., 2011; Mueller et al., 2015). According to Beck's cognitive theory of depression (Beck et al., 1979), depressed patients have a "negativity bias", tending to focus more on negative information. This leads to abnormal responses to negative feedback, and yields an increase of the FRN amplitude. Although our study did not include AD patients with moderate or severe symptoms of depression, there was a significant relationship between FRN amplitude and depression scores only in AD. In $\mathrm{AD}$ patients, the "negativity bias" might be aggravated, even in mild depression.

Consistent with previous findings of P300 using an oddball task (Polich et al., 1990; Golob and Starr, 2000;
Yamaguchi et al., 2000; Frodl et al., 2002; Bennys et al., 2007; Lee et al., 2013), the present study indicates that P300 exhibits decreased amplitudes and delayed latency in normal aging and AD. As expected, altered P300 was associated with cognitive function scores. The P300 responses are considered to be related to attention and memory processes (Polich, 2007); therefore, lower amplitudes and delayed latency of P300 in AD patients exhibits electrophysiological reflection of attention and memory deficits (Phillips et al., 2004; Bennys et al., 2007; Lai et al., 2010). It is considered that the causes of amplitude reduction in the $\mathrm{AD}$ group is atrophy of the hippocampus, decreases in blood flow, and decreases in functional binding. Because similar results were obtained in our gambling task, instead of an oddball task, the gambling task may be a more useful clinical tool in evaluating both FRN and P300 at the same time.

Our study has some limitations. First, we investigated only the alteration of FRN, but not of ERN. It has been speculated that generator sources of FRN and ERN components are located in the anterior cingulate cortex (Gehring et al., 1993; Dehaene et al., 1994; Gehring, 2002; Holroyd and Coles, 2002; Holroyd et al., 2002; Luu et al., 2003), and both potentials are associated with the monitoring system. FRN and ERN have been linked to the monitoring of externally provided and internally generated information, respectively (Müller et al., 2005). Therefore, in order to study abnormalities of the monitoring system in $\mathrm{AD}$, it would be most interesting to examine the changes of both potentials simultaneously. Second, we have not explored any abnormalities of FRN in other cognitive impairment and dementia conditions, i.e., in mild cognitive impairment (MCI), frontotemporal dementia, or dementia with Lewy bodies. It is important to examine FRN changes in MCI, because MCI is a prodromal stage of AD. Several studies have reported that MCI patients show a reduction in P300 amplitude compared to healthy elderly people (Papaliagkas et al., 2008, 2011). Therefore, it is possible that similar ERP changes may occur in MCI, and thus whether FRN amplitude increases in MCI patients should be confirmed.

\section{CONCLUSIONS}

In sum, the present study demonstrated that the FRN in $\mathrm{AD}$ patients showed larger amplitude and delayed latency compared to age-matched controls, and correlated with depressive tendency. This indicates that enhanced monitoring response in $\mathrm{AD}$ patients might reflect a compensatory mechanism and/or negative bias in outcome evaluation. Psychophysiological measures in the feedback process could provide a clue to understand the neurobehavioral changes in $\mathrm{AD}$ patients.

\section{AUTHOR CONTRIBUTIONS}

EN, KO and SY designed the study and wrote the manuscript. $\mathrm{EN}, \mathrm{FI}$ and RO collected the data. EN and KO performed the analysis. All authors listed, have made substantial, direct and intellectual contribution to the work, and approved it for publication. 


\section{REFERENCES}

Ahiskali, M., Green, D., Kounios, J., Clark, C. M., and Polikar, R. (2009). ERP based decision fusion for $\mathrm{AD}$ diagnosis across cohorts. Conf. Proc. IEEE Eng. Med. Biol. Soc. 2009, 2494-2497. doi: 10.1109/IEMBS.2009.5335141

Alvarez, J. A., and Emory, E. (2006). Executive function and the frontal lobes: a meta-analytic review. Neuropsychol. Rev. 16, 17-42. doi: 10.1007/s11065-0069002-x

Bäckman, L., Ginovart, N., Dixon, R. A., Wahlin, T.-B. R., Wahlin, A., Halldin, C., et al. (2000). Age-related cognitive deficits mediated by changes in the stratal dopamine system. Am. J. Psychiatry 157, 635-637. doi: 10.1176/ajp.157.4.635

Bailly, M., Destrieux, C., Hommet, C., Mondon, K., Cottier, J. P., Beaufils, E., et al. (2015). Precuneus and cingulate cortex atrophy and hypometabolism in patients with Alzheimer's disease and mild cognitive impairment: MRI and ${ }^{(18)}$ F-FDG PET quantitative analysis using freesurfer. Biomed. Res. Int. 2015:583931. doi: $10.1155 / 2015 / 583931$

Beck, A. T., Rush, A. J., Shaw, B. F., and Emery, G. (1979). Cognitive Therapy of Depression. New York, NY: Guilford Press.

Becker, M. P. I., Nitsch, A. M., Miltner, W. H. R., and Straube, T. (2014). A single-trial estimation of the feedback-related negativity and its relation to BOLD responses in a time-estimation task. J. Neurosci. 34, 3005-3012. doi: 10.1523/JNEUROSCI.3684-13.2014

Becker, D. E., and Shapiro, D. (1980). Directing attention toward stimuli affects the P300 but not the orienting response. Psychophysiology 17, 385-389. doi: $10.1111 /$ j.1469-8986.1980.tb00168.x

Bellebaum, C., and Daum, I. (2008). Learning-related changes in reward expectancy are reflected in the feedback-related negativity. Eur. J. Neurosci. 27, 1823-1835. doi: 10.1111/j.1460-9568.2008.06138.x

Bellebaum, C., Kobza, S., Thiele, S., and Daum, I. (2011). Processing of expected and unexpected monetary performance outcomes in healthy older subjects. Behav. Neurosci. 125, 241-251. doi: 10.1037/a0022536

Bellebaum, C., Polezzi, D., and Daum, I. (2010). It is less than you expected: the feedback-related negativity reflects violations of reward magnitude expectations. Neuropsychologia 48, 3343-3350. doi: 10.1016/j. neuropsychologia.2010.07.023

Bennys, K., Portet, F., Touchon, J., and Rondouin, G. (2007). Diagnostic value of event-related evoked potentials N200 and P300 subcomponents in early diagnosis of Alzheimer's disease and mild cognitive impairment. J. Clin. Neurophysiol. 24, 405-412. doi: 10.1097/WNP.0b013e31815068d5

Bloom, G. S. (2014). Amyloid- $\beta$ and tau: the trigger and bullet in Alzheimer disease pathogenesis. JAMA Neurol. 71, 505-508. doi: 10.1001/jamaneurol.2013.5847

Boublay, N., Schott, A. M., and Krolak-Salmon, P. (2016). Neuroimaging correlates of neuropsychiatric symptoms in Alzheimer's disease: a review of 20 years of research. Eur. J. Neurol. 23, 1500-1509. doi: 10.1111/ene.13076

Bracco, L., Bessi, V., Piccini, C., Mosconi, L., Pupi, A., and Sorbi, S. (2007). Metabolic correlates of executive dysfunction: different patterns in mild and very mild Alzheimer's disease. J. Neurol. 254, 1052-1065. doi: 10.1007/s00415006-0488-1

Buckner, R. L., Snyder, A. Z., Shannon, B. J., LaRossa, G., Sachs, R., Fotenos, A. F., et al. (2005). Molecular, structural, and functional characterization of Alzheimer's disease: evidence for a relationship between default activity, amyloid, and memory. J. Neurosci. 25, 7709-7717. doi: 10.1523/JNEUROSCI. 2177-05.2005

Cavanagh, J. F., Bismark, A. J., Frank, M. J., and Allen, J. J. B. (2011). Larger error signals in major depression are associated with better avoidance learning. Front. Psychol. 2:331. doi: 10.3389/fpsyg.2011.00331

Chan, R., Shum, D., Toulopoulou, T., and Chen, E. (2008). Assessment of executive functions: review of instruments and identification of critical issues. Arch. Clin. Neuropsychol. 23, 201-216. doi: 10.1016/j.acn.2007.08.010

Chapman, R. M., McCrary, J. W., Gardner, M. N., Sandoval, T. C., Guillily, M. D., Reilly, L. A., et al. (2011). Brain ERP components predict which individuals progress to Alzheimer's disease and which do not. Neurobiol. Aging 32, 1742-1755. doi: 10.1016/j.neurobiolaging.2009.11.010

Cohen, M. X., Elger, C. E., and Ranganath, C. (2007). Reward expectation modulates feedback-related negativity and EEG spectra. Neuroimage 35, 968-978. doi: 10.1016/j.neuroimage.2006.11.056

Collette, F., Van der Linden, M., and Salmon, E. (1999). Executive dysfunction in Alzheimer's disease. Cortex 35, 57-72. doi: 10.1016/S0010-9452(08)70785-8
Dehaene, S., Posner, M. I., and Tucker, D. M. (1994). Localization of a neural system for error detection and compensation. Psychol. Sci. 5, 303-305. doi: 10.1111/j.1467-9280.1994.tb00630.x

Diamond, A. (2013). Executive functions. Annu. Rev. Psychol. 64, 135-168. doi: 10.1146/annurev-psych-113011-143750

Donchin, E. (1981). Surprise!... Surprise? Psychophysiology 18, 493-513. doi: 10.1111/j.1469-8986.1981.tb01815.x

Dubois, B., Slachevsky, A., Litvan, I., and Pillon, B. (2000). The FAB: a frontal assessment battery at bedside. Neurology 55, 1621-1626. doi: 10.1212/wnl.55. 11.1621

Dukart, J., Kherif, F., Mueller, K., Adaszewski, S., Schroeter, M. L., Frackowiak, R. S. J., et al. (2013). Generative FDG-PET and MRI model of aging and disease progression in Alzheimer's disease. PLoS Comput. Biol. 9:e1002987. doi: 10.1371/journal.pcbi.1002987

Duncan-Johnson, C. C., and Donchin, E. (1982). The P300 component of the event-related brain potential as an index of information processing. Biol. Psychol. 14, 1-52. doi: 10.1016/0301-0511(82)90016-3

Endrass, T., Schreiber, M., and Kathmann, N. (2012). Speeding up older adults: age-effects on error processing in speed and accuracy conditions. Biol. Psychol. 89, 426-432. doi: 10.1016/j.biopsycho.2011.12.005

Eppinger, B., Kray, J., Mock, B., and Mecklinger, A. (2008). Better or worse than expected? Aging, learning, and the ERN. Neuropsychologia 46, 521-539. doi: 10.1016/j.neuropsychologia.2007.09.001

Fabiani, M., Karis, D., and Donchin, E. (1990). Effects of mnemonic strategy manipulation in a Von Restorff paradigm. Electroencephalogr. Clin. Neurophysiol. 75, 22-35. doi: 10.1016/0013-4694(90)90149-e

Falkenstein, M., Hoormann, J., Christ, S., and Hohnsbein, J. (2000). ERP components on reaction errors and their functional significance: a tutorial. Biol. Psychol. 51, 87-107. doi: 10.1016/s0301-0511(99)00031-9

Falkenstein, M., Hoormann, J., and Hohnsbein, J. (2001). Changes of errorrelated ERPs with age. Exp. Brain Res. 138, 258-262. doi: 10.1007/s0022101 00712

Folstein, M. F., Folstein, S. E., and McHugh, P. R. (1975). "Mini-mental state". A practical method for grading the cognitive state of patients for the clinician. J. Psychiatr. Res. 12, 189-198. doi: 10.1016/0022-3956(75)90026-6

Frodl, T., Hampel, H., Juckel, G., Bürger, K., Padberg, F., Engel, R. R., et al. (2002). Value of event-related P300 subcomponents in the clinical diagnosis of mild cognitive impairment and Alzheimer's disease. Psychophysiology 39, 175-181. doi: $10.1017 /$ S0048577202010260

Gehring, W. J. (2002). The medial frontal cortex and the rapid processing of monetary gains and losses. Science 295, 2279-2282. doi: 10.1126/science. 1066893

Gehring, W. J., Goss, B., Coles, M. G. H., Meyer, D. E., and Donchin, E. (1993). A neural system for error detection and compensation. Psychol. Sci. 4, 385-390. doi: 10.1111/j.1467-9280.1993.tb00586.x

Gehring, W. J., and Knight, R. T. (2000). Prefrontal-cingulate interactions in action monitoring. Nat. Neurosci. 3, 516-520. doi: 10.1038/74899

Gironell, A., García-Sánchez, C., Estévez-González, A., Boltes, A., and Kulisevsky, J. (2005). Usefulness of p300 in subjective memory complaints: a prospective study. J. Clin. Neurophysiol. 22, 279-284. doi: 10.1097/01.wnp. 0000173559.60113.ab

Golob, E. J., Irimajiri, R., and Starr, A. (2007). Auditory cortical activity in amnestic mild cognitive impairment: relationship to subtype and conversion to dementia. Brain 130, 740-752. doi: 10.1093/brain/awl375

Golob, E. J., and Starr, A. (2000). Effects of stimulus sequence on eventrelated potentials and reaction time during target detection in Alzheimer's disease. Clin. Neurophysiol. 111, 1438-1449. doi: 10.1016/s1388-2457(00) 00332-1

Gonsalvez, C. L., and Polich, J. (2002). P300 amplitude is determined by target-totarget interval. Psychophysiology 39, 388-396. doi: 10.1017/S0048577201393137

Grady, C. (2012). The cognitive neuroscience of ageing. Nat. Rev. Neurosci. 13, 491-505. doi: 10.1038/nrn3256

Greicius, M. D., Srivastava, G., Reiss, A. L., and Menon, V. (2004). Defaultmode network activity distinguishes Alzheimer's disease from healthy aging: evidence from functional MRI. Proc. Natl. Acad. Sci. U S A 101, 4637-4642. doi: $10.1073 /$ pnas. 0308627101

Groen, Y., Wijers, A. A., Mulder, L. J. M., Waggeveld, B., Minderaa, R. B., and Althaus, M. (2008). Error and feedback processing in children with ADHD and 
children with autistic spectrum disorder: an EEG event-related potential study. Clin. Neurophysiol. 119, 2476-2493. doi: 10.1016/j.clinph.2008.08.004

Hafkemeijer, A., Möller, C., Dopper, E. G. P., Jiskoot, L. C., van den Berg-Huysmans, A. A., van Swieten, J. C., et al. (2016a). A longitudinal study on resting state functional connectivity in behavioral variant frontotemporal dementia and Alzheimer's disease. J. Alzheimers Dis. 55, 521-537. doi: 10.3233/jad-150695

Hafkemeijer, A., Möller, C., Dopper, E. G. P., Jiskoot, L. C., van denBerg-Huysmans, A. A., van Swieten, J. C., et al. (2016b). Differences in structural covariance brain networks between behavioral variant frontotemporal dementia and Alzheimer's disease. Hum. Brain Mapp. 37, 978-988. doi: 10.1002/hbm.23081

Hajcak, G., Moser, J. S., Holroyd, C. B., and Simons, R. F. (2006). The feedbackrelated negativity reflects the binary evaluation of good versus bad outcomes. Biol. Psychol. 71, 148-154. doi: 10.1016/j.biopsycho.2005.04.001

Hajcak, G., Moser, J. S., Holroyd, C. B., and Simons, R. F. (2007). It's worse than you thought: the feedback negativity and violations of reward prediction in gambling tasks. Psychophysiology 44, 905-912. doi: 10.1111/j.1469-8986.2007. 00567.x

Halgren, E., Marinkovic, K., and Chauvel, P. (1998). Generators of the late cognitive potentials in auditory and visual oddball tasks. Electroencephalogr. Clin. Neurophysiol. 106, 156-164. doi: 10.1016/s0013-4694(97)00119-3

Hämmerer, D., Li, S. C., Müller, V., and Lindenberger, U. (2011). Life span differences in electrophysiological correlates of monitoring gains and losses during probabilistic reinforcement learning. J. Cogn. Neurosci. 23, 579-592. doi: 10.1162/jocn.2010.21475

Holroyd, C. B., Baker, T. E., Kerns, K. A., and Müller, U. (2008). Electrophysiological evidence of atypical motivation and reward processing in children with attention-deficit hyperactivity disorder. Neuropsychologia 46, 2234-2242. doi: 10.1016/j.neuropsychologia.2008.02.011

Holroyd, C. B., and Coles, M. G. H. (2002). The neural basis of human error processing: reinforcement learning, dopamine and the error-related negativity. Psychol. Rev. 109, 679-709. doi: 10.1037//0033-295x.109.4.679

Holroyd, C. B., Coles, M. G. H., and Nieuwenhuis, S. (2002). Medial prefrontal cortex and error potentials. Science 296, 1610-1611. doi: 10.1126/science.296. 5573.1610

Holroyd, C. B., Hajcak, G., and Larsen, J. T. (2006). The good, the bad and the neutral: electrophysiological responses to feedback stimuli. Brain Res. 1105, 93-101. doi: 10.1016/j.brainres.2005.12.015

Holroyd, C. B., Krigolson, O. E., Baker, R., Lee, S. H., and Gibson, J. (2009). When is an error not a prediction error? An electrophysiological investigation. Cogn. Affect. Behav. Neurosci. 9, 59-70. doi: 10.3758/CABN.9.1.59

Howe, A. S., Bani-Fatemi, A., and De Luca, V. (2014). The clinical utility of the auditory P300 latency subcomponent event-related potential in preclinical diagnosis of patients with mild cognitive impairment and Alzheimer's disease. Brain Cogn. 86, 64-74. doi: 10.1016/j.bandc.2014.01.015

Johnson, R. Jr. (1995). "Event-related potential insights into the neurobiology of memory systems," in The Handbook of Neuropsychology (Vol. 10), F. Boller and J. Grafman (Amsterdam: Elsevier Science Publishers), $135-164$.

Jones, B. F., Barnes, J., Uylings, H. B. M., Fox, N. C., Frost, C., Witter, M. P., et al. (2006). Differential regional atrophy of the cingulate gyrus in Alzheimer disease: a volumetric MRI study. Cereb. Cortex 16, 1701-1708. doi: 10.1093/cercor/bhj105

Juckel, G., Clotz, F., Frodl, T., Kawohl, W., Hampel, H., Pogarell, O., et al. (2008). Diagnostic usefulness of cognitive auditory event-related p300 subcomponents in patients with Alzheimers disease? J. Clin. Neurophysiol. 25, 147-152. doi: 10.1097/WNP.0b013e3181727c95

Kaasinen, V., Vilkman, H., Hietala, J., Någren, K., Helenius, H., Olsson, H., et al. (2000). Age-related dopamine D2/D3 receptor loss in extrastriatal regions of the human brain. Neurobiol. Aging 21, 683-688. doi: 10.1016/s0197$4580(00) 00149-4$

Karis, D., Fabiani, M., and Donchin, E. (1984). "P300" and memory: individual differences in the von Restorff effect. Cogn. Psychol. 16, 177-216. doi: 10.1016/0010-0285(84)90007-0

Katada, E., Sato, K., Ojika, K., and Ueda, R. (2004). Cognitive event-related potentials: useful clinical information in Alzheimer's disease. Curr. Alzheimer Res. 1, 63-69. doi: 10.2174/1567205043480609
Kiehl, K., Laurens, K. R., Duty, T. L., Forster, B. B., and Liddle, P. F. (2001). Neural sources involved in auditory target detection and novelty processing: an event-related fMRI study. Psychophysiology 38, 133-142. doi: $10.1017 / \mathrm{s} 0048577201981867$

Kirino, E., Belger, A., Goldman-Rakic, P., and McCarthy, G. (2000). Prefrontal activation evoked by infrequent target and novel stimuli in a visual target detection task: an event-related functional magnetic resonance imaging study. J. Neurosci. 20, 6612-6618.

Kramer, A. F., and Strayer, D. L. (1988). Assessing the development of automatic processing: an application of dual-task and event-related brain potential methodologies. Biol. Psychol. 26, 231-267. doi: 10.1016/0301-0511(88)9 0022-1

Kramer, A. F., Wickens, C. D., and Donchin, E. (1985). Processing of stimulus properties: evidence for dual-task integrality. J. Exp. Psychol. Hum. Percept. Perform. 11, 393-408. doi: 10.1037//0096-1523.11.4.393

Krueger, C. E., Dean, D. L., Rosen, H. J., Halabi, C., Weiner, M., Miller, B. L., et al. (2010). Longitudinal rates of lobar atrophy in frontotemporal dementia, semantic dementia and Alzheimer's disease. Alzheimer Dis. Assoc. Disord. 24, 43-48. doi: 10.1097/WAD.0b013e3181a6f101

Kutas, M., McCarthy, G., and Donchin, E. (1977). Augmenting mental chronometry: the P300 as a measure of stimulus evaluation time. Science 197, 792-795. doi: 10.1126/science.887923

Lai, C. L., Lin, R. T., Liou, L. M., and Liu, C. K. (2010). The role of event-related potentials in cognitive decline in Alzheimer's disease. Clin. Neurophysiol. 121, 194-199. doi: 10.1016/j.clinph.2009.11.001

Larson, M. J., and Clayson, P. E. (2011). The relationship between cognitive performance and electrophysiological indices of performance monitoring. Cogn. Affect. Behav. Neurosci. 11, 159-171. doi: 10.3758/s13415-010-0018-6

Larson, M. J., South, M., Krauskopf, E., Clawson, A., and Crowley, M. J. (2011). Feedback and reward processing in high-functioning autism. Psychiatry Res. 187, 198-203. doi: 10.1016/j.psychres.2010.11.006

Lee, M., Lee, S., Moon, E., Moon, Y., Kim, S., Kim, S., et al. (2013). Neuropsychological correlates of the P300 in patients with Alzheimer's disease. Prog. Neuropsychopharmacol. Biol. Psychiatry 40, 62-69. doi: 10.1016/j.pnpbp. 2012.08.009

Leuba, G., Vernay, A., Zimmermann, V., Saini, K., Kraftsik, R., and Savioz, A. (2009). Differential damage in the frontal cortex with aging, sporadic and familial Alzheimer's disease. Brain Res. Bull. 80, 196-202. doi: 10.1016/j. brainresbull.2009.06.009

Lim, T. S., Hong, Y. H., Lee, H. Y., Choi, J. Y., Kim, H. S., and Moon, S. Y. (2012). Metabolite investigation in both anterior and posterior cingulate gyri in Alzheimer's disease spectrum using 3-tesla MR spectroscopy. Dement. Geriatr. Cogn. Disord. 33, 149-155. doi: 10.1159/000338177

Lin, Y. C., Shih, Y. C., Tseng, W. Y. I., Chu, Y. H., Wu, M. T., Chen, T. F., et al. (2014). Cingulum correlates of cognitive functions in patients with mild cognitive impairment and early Alzheimer's disease: a diffusion spectrum imaging study. Brain Topogr. 27, 393-402. doi: 10.1007/s10548-0130346-2

Long, X., Zhang, L., Liao, W., Jiang, C., Qiu, B., and Alzheimer's Disease Neuroimaging Initiative. (2013). Distinct laterality alterations distinguish mild cognitive impairment and Alzheimer's disease from healthy aging: statistical parametric mapping with high resolution MRI. Hum. Brain Mapp. 34, 3400-3410. doi: 10.1002/hbm.22157

Luu, P., Tucker, D. M., Derryberry, D., Reed, M., and Poulsen, C. (2003). Electrophysiological responses to errors and feedback. Psychol. Sci. 14, 47-53. doi: 10.1111/1467-9280.01417

Mathalon, D. H., Bennett, A., Askari, N., Gray, E. M., Rosenbloom, M. J., and Ford, J. M. (2003). Response-monitoring dysfunction in aging and Alzheimer's disease: an event-related potential study. Neurobiol. Aging 24, 675-685. doi: 10.1016/s0197-4580(02)00154-9

Mathewson, K. J., Dywan, J., Snyder, P. J., Tays, W. J., and Segalowitz, S. J. (2008). Aging and electrocortical response to error feedback during a spatial learning task. Psychophysiology 45, 936-948. doi: 10.1111/j.1469-8986.2008.00699.x

McMahon, C. M., and Henderson, H. A. (2015). Error-monitoring in response to social stimuli in individuals with higher-functioning Autism Spectrum Disorder. Dev. Sci. 18, 389-403. doi: 10.1111/desc.12220

McPartland, J. C., Crowley, M. J., Perszyk, D. R., Mukerji, C. E., Naples, A. J., $\mathrm{Wu}$, J., et al. (2012). Preserved reward outcome processing in ASD as revealed 
by event-related potentials. J. Neurodev. Disord. 4:16. doi: 10.1186/1866-19 55-4-16

Miltner, W. H., Braun, C. H., and Coles, M. G. (1997). Event-related brain potentials following incorrect feedback in a time-estimation task: evidence for a "generic" neural system for error detection. J. Cogn. Neurosci. 9, 788-798. doi: 10.1162/jocn.1997.9.6.788

Morishima-Kawashima, M., and Ihara, Y. (2002). Alzheimer's disease: $\beta$-Amyloid protein and tau. J. Neurosci. Res. 70, 392-401. doi: 10.1002/jnr.10355

Mueller, E. M., Pechtel, P., Cohen, A. L., Douglas, S. R., and Pizzagalli, D. A. (2015). Potentiated processing of negative feedback in depression is attenuated by anhedonia. Depress. Anxiety 32, 296-305. doi: 10.1002/da.22338

Müller, S. V., Möller, J., Rodriguez-Fornells, A., and Münte, T. F. (2005). Brain potentials related to self-generated and external information used for performance monitoring. Clin. Neurophysiol. 116, 63-74. doi: 10.1016/j.clinph.2004.07.009

Murphy, M. P., and LeVine, H. III (2010). Alzheimer's disease and the amyloid- $\beta$ peptide. J. Alzheimers Dis. 19, 311-323. doi: 10.3233/JAD-2010-1221

Nieuwenhuis, S., Holroyd, C. B., Mol, N., and Coles, M. G. H. (2004). Reinforcement-related brain potentials from medial frontal cortex: origins and functional significance. Neurosci. Biobehav. Rev. 28, 441-448. doi: 10.1016/j. neubiorev.2004.05.003

Nieuwenhuis, S., Ridderinkhof, K. R., Talsma, D., Coles, M. G. H., Holroyd, C. B., Kok, A., et al. (2002). A computational account of altered error processing in older age: dopamine and the error-related negativity. Cogn. Affect. Behav. Neurosci. 2, 19-36. doi: 10.3758/cabn.2.1.19

Okada, K., Kobayashi, S., Aoki, K., Suyama, N., and Yamagata, S. (1998). Assessment of motivational loss in poststroke patients using the Japanese version of Starkstein's Apathy Scale. Japanese J. Stroke 20, 318-323. doi: $10.3995 /$ jstroke.20.318

Olichney, J. M., Yang, J. C., Taylor, J., and Kutas, M. (2011). Cognitive eventrelated potentials: biomarkers of synaptic dysfunction across the stages of Alzheimer's disease. J. Alzheimers Dis. 26, 215-228. doi: 10.3233/JAD-20 11-0047

Ott, B. R., Lafleche, G., Whelihan, W. M., Buongiorno, G. W., Albert, M. S., and Fogel, B. S. (1996). Impaired awareness of deficits in Alzheimer disease. Alzheimer Dis. Assoc. Disord. 10, 68-76. doi: 10.1097/00002093-19960102000003

Papaliagkas, V., Kimiskidis, V., Tsolaki, M., and Anogianakis, G. (2008). Usefulness of event-related potentials in the assessment of mild cognitive impairment. BMC Neurosci. 9:107. doi: 10.1186/1471-2202-9-107

Papaliagkas, V. T., Kimiskidis, V. K., Tsolaki, M. N., and Anogianakis, G. (2011). Cognitive event-related potentials: longitudinal changes in mild cognitive impairment. Clin. Neurophysiol. 122, 1322-1326. doi: 10.1016/j.clinph.2010. 12.036

Parra, M. A., Ascencio, L. L., Urquina, H. F., Manes, F., and Ibáñez, A. M. (2012). P300 and neuropsychological assessment in mild cognitive impairment and alzheimer dementia. Front. Neurol. 3:172. doi: 10.3389/fneur.2012.00172

Perry, R. J., and Hodges, J. R. (1999). Attention and executive deficits in Alzheimer's disease. A critical review. Brain 122, 383-404. doi: 10.1093/brain/122.3.383

Phillips, N. A., Chertkow, H., Leblanc, M. M., Pim, H., and Murtha, S. (2004). Functional and anatomical memory indices in patients with or at risk for Alzheimer's disease. J. Int. Neuropsychol. Soc. 10, 200-210. doi: $10.1017 /$ S1355617704102063

Pietschmann, M., Endrass, T., Czerwon, B., and Kathmann, N. (2011a). Aging, probabilistic learning and performance monitoring. Biol. Psychol. 86, 74-82. doi: 10.1016/j.biopsycho.2010.10.009

Pietschmann, M., Endrass, T., and Kathmann, N. (2011b). Age-related alterations in performance monitoring during and after learning. Neurobiol. Aging 32, 1320-1330. doi: 10.1016/j.neurobiolaging.2009.07.016

Polich, J. (1986). Attention, probability and task demands as determinants of P300 latency from auditory stimuli. Electroencephalogr. Clin. Neurophysiol. 63, 251-259. doi: 10.1016/0013-4694(86)90093-3

Polich, J. (2004). Clinical application of the P300 event-related brain potential. Phys. Med. Rehabil. Clin. N. Am. 15, 133-161. doi: 10.1016/s10479651(03)00109-8

Polich, J. (2007). Updating P300: an integrative theory of P3a and P3b. Clin. Neurophysiol. 118, 2128-2148. doi: 10.1016/j.clinph.2007.04.019
Polich, J., and Corey-Bloom, J. (2005). Alzheimer's disease and P300: review and evaluation of task and modality. Curr. Alzheimer Res. 2, 515-525. doi: $10.2174 / 156720505774932214$

Polich, J., Ladish, C., and Bloom, F. E. (1990). P300 assessment of early Alzheimer's disease. Electroencephalogr. Clin. Neurophysiol. 77, 179-189. doi: 10.1016/01685597(90)90036-d

Rombouts, S. A. R. B., Barkhof, F., Goekoop, R., Stam, C. J., and Scheltens, P. (2005). Altered resting state networks in mild cognitive impairment and mild Alzheimer's disease: an fMRI study. Hum. Brain Mapp. 26, 231-239. doi: $10.1002 / \mathrm{hbm} .20160$

Santesso, D. L., Drmic, I. E., Jetha, M. K., Bryson, S. E., Goldberg, J. O., Hall, G. B., et al. (2011). An event-related source localization study of response monitoring and social impairments in autism spectrum disorder. Psychophysiology 48, 241-251. doi: 10.1111/j.1469-8986.2010.01056.x

Santesso, D. L., Steele, K. T., Bogdan, R., Holmes, A. J., Deveney, C. M., Meites, T. M., et al. (2008). Enhanced negative feedback responses in remitted depression. Neuroreport 19, 1045-1048. doi: 10.1097/WNR.0b013e32830 $36 \mathrm{e} 73$

Schreiber, M., Pietschmann, M., Kathmann, N., and Endrass, T. (2011). ERP correlates of performance monitoring in elderly. Brain Cogn. 76, 131-139. doi: 10.1016/j.bandc.2011.02.003

Seeley, W. W., Crawford, R. K., Zhou, J., Miller, B. L., and Greicius, M. D. (2009). Neurodegenerative diseases target large-scale human brain networks. Neuron 62, 42-52. doi: 10.1016/j.neuron.2009.03.024

Seeley, W. W., Menon, V., Schatzberg, A. F., Keller, J., Glover, G. H., Kenna, H., et al. (2007). Dissociable intrinsic connectivity networks for salience processing and executive control. J. Neurosci. 27, 2349-2356. doi: 10.1523/JNEUROSCI. 5587-06.2007

Sinz, H., Zamarian, L., Benke, T., Wenning, G. K., and Delazer, M. (2008). Impact of ambiguity and risk on decision making in mild Alzheimer's disease. Neuropsychologia 46, 2043-2055. doi: 10.1016/j.neuropsychologia.2008. 02.002

Sokhadze, E., Baruth, J., El-Baz, A., Horrell, T., Carroll, T., Tasman, A., et al. (2011). Impaired error monitoring and correction function in autism. J. Neurother. 14, 79-95. doi: 10.1080/10874201003771561

Sokhadze, E. M., Baruth, J. M., Sears, L., Sokhadze, G. E., El-Baz, A. S., Williams, E., et al. (2012). Event-related potential study of attention regulation during illusory figure categorization task in ADHD, autism spectrum disorder and typical children. J. Neurother. 16, 12-31. doi: 10.1080/10874208.2012. 650119

South, M., Larson, M. J., Krauskopf, E., and Clawson, A. (2010). Error processing in high-functioning autism spectrum disorders. Biol. Psychol. 85, 242-251. doi: 10.1016/j.biopsycho.2010.07.009

Stavropoulos, K. K. M., and Carver, L. J. (2014). Reward anticipation and processing of social versus nonsocial stimuli in children with and without autism spectrum disorders. J. Child Psychol. Psychiatry 55, 1398-1408. doi: $10.1111 /$ jcpp. 12270

Sutton, S., Braren, M., Zubin, J., and John, E. R. (1965). Evoked-potential correlates of stimulus uncertainty. Science 150, 1187-1188. doi: 10.1126/science.150.37 00.1187

Tarkka, I. M., and Stokic, D. S. (1998). Source localization of P300 from oddball, single stimulus and omitted-stimulus paradigms. Brain Topogr. 11, 141-151. doi: 10.1023/A:1022258606418

Terada, S., Sato, S., Nagao, S., Ikeda, C., Shindo, A., Hayashi, S., et al. (2013). Trail making test $B$ and brain perfusion imaging in mild cognitive impairment and mild Alzheimer's disease. Psychiatry Res. 213, 249-255. doi: 10.1016/j. pscychresns.2013.03.006

Tucker, D. M., Luu, P., Frishkoff, G., Quiring, J., and Poulsen, C. (2003). Frontolimbic response to negative feedback in clinical depression. J. Abnorm. Psychol. 112, 667-678. doi: 10.1037/0021-843x.112.4.667

van Meel, C. S., Heslenfeld, D. J., Oosterlaan, J., Luman, M., and Sergeant, J. A. (2011). ERPs associated with monitoring and evaluation of monetary reward and punishment in children with ADHD. J. Child Psychol. Psychiatry 52, 942-953. doi: 10.1111/j.1469-7610.2010.02352.x

van Meel, C. S., Oosterlaan, J., Heslenfeld, D. J., and Sergeant, J. A. (2005). Telling good from bad news: ADHD differentially affects processing of positive and negative feedback during guessing. Neuropsychologia 43, 1946-1954. doi: 10.1016/j.neuropsychologia.2005.03.018 
Vecchio, F., and Määttä, S. (2011). The use of auditory event-related potentials in Alzheimer's disease diagnosis. Int. J. Alzheimers Dis. 2011:653173. doi: $10.4061 / 2011 / 653173$

Vlamings, P. H. J. M., Jonkman, L. M., Hoeksma, M. R., van Engeland, H., and Kemner, C. (2008). Reduced error monitoring in children with autism spectrum disorder: an ERP study. Eur. J. Neurosci. 28, 399-406. doi: 10.1111/j. 1460-9568.2008.06336.x

Volkow, N. D., Gur, R. C., Wang, G. J., Fowler, J. S., Moberg, P. J., Ding, Y., et al. (1998). Association between declines in brain dopamine activity with age and cognitive and motor impairment in healthy individuals. Am. J. Psychiatry 155, 344-349.

Wang, K., Liang, M., Wang, L., Tian, L., Zhang, X., Li, K., et al. (2007). Altered functional connectivity in early Alzheimer's disease: a restingstate fMRI study. Hum. Brain Mapp. 28, 967-978. doi: 10.1002/hbm. 20324

Wickens, C., Kramer, A., Vanasse, L., and Donchin, E. (1983). Performance of concurrent tasks: a psychophysiological analysis of the reciprocity of information-processing resources. Science 221, 1080-1082. doi: $10.1126 /$ science. 6879207

Wild-Wall, N., Willemssen, R., and Falkenstein, M. (2009). Feedback-related processes during a time-production task in young and older adults. Clin. Neurophysiol. 120, 407-413. doi: 10.1016/j.clinph.2008.11.007

Wu, Y., and Zhou, X. (2009). The P300 and reward valence, magnitude and expectancy in outcome evaluation. Brain Res. 1286, 114-122. doi: 10.1016/j. brainres.2009.06.032

Yamaguchi, S., and Knight, R. T. (1991a). Anterior and posterior association cortex contributions to the somatosensory P300. J. Neurosci. 11, 2039-2054.
Yamaguchi, S., and Knight, R. T. (1991b). P300 generation by novel somatosensory stimuli. Electroencephalogr. Clin. Neurophysiol. 78, 50-55. doi: 10.1016/00134694(91)90018-y

Yamaguchi, S., Tsuchiya, H., Yamagata, S., Toyoda, G., and Kobayashi, S. (2000). Event-related brain potentials in response to novel sounds in dementia. Clin. Neurophysiol. 111, 195-203. doi: 10.1016/s1388-2457(99)00228-x

Yeung, N., and Sanfey, A. G. (2004). Independent coding of reward magnitude and valence in the human brain. J. Neurosci. 24, 6258-6264. doi: 10.1523/JNEUROSCI.4537-03.2004

Zhou, J., Greicius, M. D., Gennatas, E. D., Growdon, M. E., Jang, J. Y., Rabinovici, G. D., et al. (2010). Divergent network connectivity changes in behavioural variant frontotemporal dementia and Alzheimer's disease. Brain 133, 1352-1367. doi: 10.1093/brain/awq075

Zung, W. W. (1965). A self-rating depression scale. Arch. Gen. Psychiatry 12, 63-70. doi: 10.1001/archpsyc.1965.01720310065008

Conflict of Interest Statement: The authors declare that the research was conducted in the absence of any commercial or financial relationships that could be construed as a potential conflict of interest.

Copyright (C) 2017 Nitta, Onoda, Ishitobi, Okazaki, Mishima, Nagai and Yamaguchi. This is an open-access article distributed under the terms of the Creative Commons Attribution License (CC BY). The use, distribution or reproduction in other forums is permitted, provided the original author(s) or licensor are credited and that the original publication in this journal is cited, in accordance with accepted academic practice. No use, distribution or reproduction is permitted which does not comply with these terms. 